\title{
Strain Effect On Microstructural Properties Of SUS 304L Joint By PAW+GTAW
}

\section{Juan Wang ( $\sim$ jwang@sdu.edu.cn )}

Edison Welding Institute

\section{Yajiang Li}

Edison Welding Institute

\section{Qi Wang}

Edison Welding Institute

Kun Liu

Edison Welding Institute

\section{Hang Li}

Edison Welding Institute

\section{Research Article}

Keywords: 304L stainless steel, PAW+GTAW, Strain, Tensile strength, Impact toughness

Posted Date: April 22nd, 2021

DOI: https://doi.org/10.21203/rs.3.rs-441510/v1

License: (c) (i) This work is licensed under a Creative Commons Attribution 4.0 International License. Read Full License

Version of Record: A version of this preprint was published at The International Journal of Advanced Manufacturing Technology on August 6th, 2021. See the published version at https://doi.org/10.1007/s00170-021-07800-1. 


\section{Abstract}

304L stainless steel was joined by a combination welding process of plasma arc welding and gas tungsten arc welding (PAW + GTAW). Then pre-strain treatment on 304L welded joint by $9 \%$ was carried out using uniaxial static tensile at room temperature. Effect of strain on microstructure evolution in joint was analyzed by field emission scanning electron microscope (FESEM) and on mechanical properties was also studied. The results indicated that the strain rate of $304 \mathrm{~L}$ joint showed inhomogeneity including $3 \%$ in the weld metal and $13 \%$ in the heat affected zone (HAZ), which induced martensitic transformation occurring in HAZ. Tensile strength of the joint increased from 700MPa as welded to $804 \mathrm{MPa}$ after strain at room temperature and it reached $1700 \mathrm{MPa}$ from $1480 \mathrm{MPa}$ at low temperature of $-196^{\circ} \mathrm{C}$. Impact toughness in $\mathrm{HAZ}$ was the least among the whole joint, but it was still $94 \mathrm{~J}$ at $-196^{\circ} \mathrm{Cafter}$ strain. The fracture surface showed large numbered of cleavage steps with elongated parabolic dimples.

\section{Introduction}

SUS 304L austenitic stainless steel is widely used for pressure vessel at low temperature due to its good comprehensive mechanical properties and excellent corrosion resistance. The permissible stress of 304L steel is usually designed to use by its yield strength considering current safety factor. Therefore, the thickness of pressure vessel is large as some heavy equipment resulting in serious waste of materials owing to its low yield strength and low bending strength ratio, which leads to high cost of manufacturing and transportation. The yield strength of $304 \mathrm{~L}$ steel can be effectively improved by pre-strain strengthening treatment to make it partially plastic deformed on the premise that the original mechanical properties of $304 \mathrm{~L}$ steel are not greatly affected[1-3]. The thickness of vessels designed by new yield strength after strain strengthening can be reduced by $20 \%-30 \%$, which is favorable to save materials, reduce costs and energy consumption in transportation[4].

Welding is the key technology in the manufacture of austenitic stainless steel pressure vessel. Submerged arc welding (SAW) and gas tungsten arc weld (GTAW) are commonly used in medium and heavy plate stainless steel vessels $[5,6]$. The heat affected zone (HAZ) in joint is wide due to the larger welding heat input by SAW, which makes the performance of HAZ greatly reduced after strain [7]. GTAW is having a major application in the important joint due to its high welding quality [8]. But its low productivity is restricted to join thick $304 \mathrm{~L}$ steel because of low welding speed. Plasma arc welding (PAW), which is a kind of fusion welding process with keyhole, is effective in joining $304 \mathrm{~L}$ steel with a thickness of $8-12 \mathrm{~mm}$ due to its high energy density heat beam $[9,10]$. But undercut and little corrosion resistance is prone to occur in weld metal because there is no filled metal during PAW. So some research on the combination of PAW and GTAW (PAW + GTAW) has been conducted to weld 304L and a good formation and mechanical properties in joint are obtained [11]. In addition, PAW + GTAW has several advantages, such as energy concentration, high operating efficiency and high welding speed as compared with single PAW or GTAW. 
$304 \mathrm{~L}$ steel joint should have high quality when it is necessary to be pre-strained. Microstructure and mechanical properties of $304 \mathrm{~L}$ joint with a thickness of $4 \mathrm{~mm}$ by PAW is hardly changed and there is still composed of austenite and $\delta$-ferrite without martensitic transformation in joint after strain by $4 \%$ [12]. Effect of strain rate on microstructural properties of 304L steel PAW joint with a thickness of $8 \mathrm{~mm}$ has also been studied and it indicated that the number of dislocations and deformation twins were increasing with hardening stress and $a^{\prime}$-martensite ( $\left.a^{\prime}-M\right)$ occured in the joint [13]. There was some dislocation with high density in the fusion zone and a lot of $a^{\prime}-M$ with twins in base metal. Impact toughness of the welded joint at low temperature was still more than the maximum value from the national standard and the impact fracture showed ductile fracture with dimple after strain strengthening [14].

In this paper, study on microstructure characteristics and mechanical properties in 304L steel joint with a thickness of $12 \mathrm{~mm}$ experiencing pre-strain by $9 \%$ has been carried out to investigate the effect of strain on tensile strength and impact toughness at $-196^{\circ} \mathrm{C}$ in the whole joint by PAW + GTAW.

\section{Experimental Design}

In this work, SUS 304L austenitic stainless steel with a thickness of $12 \mathrm{~mm}$ was used as the base metal for welding. The plate prepared for joining is $500 \mathrm{~mm} \times 300 \mathrm{~mm}$. 308LSi filler wire with a diameter of 1.0 $\mathrm{mm}$ is filled in GTAW for covering layer. The chemical compositions of base metal and wire are listed in Table 1.

Before welding, the base metal surface has been mechanically polished to remove the oxide and oil stain. The plate was provided with a $60^{\circ} \mathrm{V}$-type groove by a blunt edge of $7 \mathrm{~mm}$. Plasma arc welding (PAW) was used to weld 304L steel for the first layer by EWM-422 plasma arc welding machine of German IDA. There was no metal filled in the welding process and the plasma gas was a mixture of $97 \% \mathrm{Ar}+3 \% \mathrm{H}_{2}$. The welding parameters are given in Table 2. GTAW cover welding with filler wire was carried out after the completion of penetration welding by PAW. The wire feeding speed was $280 \mathrm{~cm} / \mathrm{min}$ and the pure argon was adopted with a flow rate of $18 \mathrm{~L} / \mathrm{min}$.

High pressure water jet was used to cut some samples for metallographic observation, pre-strain treatment and mechanical properties test along the direction perpendicular to the weld. A hydraulic universal testing machine (WE-600A) was used to conduct static tension strain by $9 \%$ on joint at room temperature, as shown in Fig. 1. The loading rate was $0.1 \mathrm{kN} / \mathrm{s}$ and the strain rate was $3 \times 10^{-4} / \mathrm{s}$.

Figure 2 shows V-notch impact test samples with dimensions of $55 \mathrm{~mm} \times 10 \mathrm{~mm} \times 10 \mathrm{~mm}$ extracted transverse to each weld. The locations notched are at the weld metal (WM), the heat affected zone (HAZ) and base metal (BM). The fractured joint samples are presented in Fig. 2c. Tensile strength and impact toughness were tested at $25^{\circ} \mathrm{C}$ and $-196^{\circ} \mathrm{C}$ in the liquid $\mathrm{N}_{2}$ according to thelS0148-1. The microstructure of the joint was analyzed by XJP-6A metallographic microscope and thermal field emission scanning electron microscope (SU-70). 


\section{Results And Discussion}

\subsection{Joint morphology and strain feature}

Figure 3 shows The morphology of 304L stainless steel joint obtained by plasma arc and argon tungsten arc welding (PAW + GTAW) process. It is found that the front GTAW weld ripple is smooth and neat and the weld pool height is uniform. There is a good fusion between both sides of base metal. Back-shaping is also got by single weld with PAW in the help of keyhole effect and the back bead is fully penetrated with a good appearance. Figure $3 \mathrm{~b}$ shows the cross-section feature of PAW + GTAW joint. The internal quality of the filled metal is uniform with deep penetration characteristics of PAW bead and a complete fusion between GTAW and PAW weld bead.

A sample with a length of $300 \mathrm{~mm}$ including filled metal and base metal was prepared for strain treatment and the total strain was $9 \%$. The surface of specimen was marked at an equal distance of $10 \mathrm{~mm}$, as shown in Fig. 4a. After strain, the distance between the every two original marked lines was measured and the result is shown in Fig. 4b. Strain varies in different region of the whole $304 \mathrm{~L}$ joint including BM, WM and HAZ. It suggests that ability to resist deformation in BM, WM and HAZ is different although the total average strain is $9 \%$.

The strain in the weld metal (WM) has a minimum value of about $3 \%$ and it has a peak value of $13 \%$ in HAZ. It is mainly related to the microstructure characteristics with different crystal lattice. Figure $5 \mathrm{a}$ shows microstructure in 304L joint got by PAW + GTAW. It can be obviously seen that there is a large number of delta ferrite $(\delta-F)$ with body-centered cubic (bcc) crystal structure in WM and austenite $(A)$ with face-centered cubic $(\mathrm{fcc})$ crystal structure in HAZ as welded.

The strain condition is known to exert a significant influence on the dislocation substructure and density [15]. There is less $\delta-F$ slip systems in bcc, which makes it easier to stack dislocations and increase deformation resistance [16]. Therefore, the strain is only $3 \%$ in WM with a lot of $\delta$-F. The larger deformation in HAZ is attributed to the weakening of austenitic grain boundary experiencing strain, as shown in Fig. 5b. Meanwhile, there are more austenite slip systems in fcc system and martensite shearing occurs in grains, which makes stress concentration relax and reduces slip resistance and it is conducive to deformation in different orientations of austenite. These results indicate that the generation of dislocations in the HAZ provides a greater strengthening effect than that in the weld metal.

\subsection{Microstructure evolution}

Figure 6 shows the microstructure comparison of 304L steel joint as welded and after strain. The distribution of delta ferrite $(\delta-F)$ in GTAW filled metal is relatively concentrated and the large part is skeletal $\delta$ - $F$ with some interfacial characteristics such as migrating grain boundary (MGB), solidified grain boundary (SGB) and solidified sub grain boundary (SSGB), as shown in Fig. 6a. The skeletal $\delta-F$ provides a greater resistance to plastic flow during strain. The microstructure in weld metal by GTAW becomes fine and dense with decreasing ferrite lath gap along the deformation, refer Fig. 6b. The interfacial characteristics with solidification grain boundary are not obvious. The structure of delta ferrite is slender 
and irregular. The fine delta ferrite introduces an increased number of dislocation sources, which act as barriers to the mobile dislocations [15].

Figure $6 \mathrm{c}$ shows the microstructure in PAW backing layer as weld and it is mainly composed of austenite $(A)$ and delta ferrite ( $\delta-F)$. Temperature in molten pool is high and the temperature gradient is large under the action of high energy plasma arc. Therefore, Austenite is generated by eutectic reaction of ferrite cell boundary and dendrite boundary. The distribution of austenite and delta ferrite in the weld metal by plasma arc is not uniform and orientation of austenite is obvious. This is because the transformation from reaction in Fe-Ni system to eutectic reaction in Fe-Cr-Ni system is greatly affected by the diffusion of solute atoms in the front of solid-liquid interface.

Figure $6 \mathrm{~d}$ shows the microstructure characteristic in the weld metal for PAW after strain. It is found that the grain in WM has been elongated along the deformation direction. The epitaxial growth of weld grain leads to the transformation from cellular dendrite to columnar grain, and there are fewer dense nonuniform shear deformation bands after strain. Some studies $[13,15]$ have shown the effect of different strain rates on the microstructure transformation of 304 stainless steel, it is revealed that these fine spacing shear bands are the product of changing the microstructure of austenitic stainless steel in the process of strain strengthening, and the dislocation in the weld is prone to pile up. In the present study, it is assumed that the difference between the closely packed lattice planes in the delta ferrite and those in the austenite does not represent the source of micro-shear band formation and martensitic nucleation. Consequently, there are fewer formations of martensite and micro-shear bands in the WM.

Some inhomogeneity of microstructure is shown in narrow HAZ affected by the welding thermal cycling shown in Fig. 7a. The grain size of HAZ is large and grain growth occurs near the high temperature zone due to the concentrated energy by plasma arc. The current high-resolution lattice image display that presence of dislocation is limited to the austenite structures shown in Fig. 7b. There is also a small amount of ferrite can be observed in the HAZ, and there is a trend of extending from the fusion zone to the HAZ along the direction of large temperature gradient. The ferrite in HAZ has no liquid-solid phase transformation but only solid phase transformation.

Figure 7c shows that there are $a^{\prime}-$ martensite $\left(a^{\prime}-M\right)$ formations and micro-shear bands in the HAZ of the weldments after strain. The formation of micro-shear bands and martensite appears to be influenced by the high density dislocation in austenite grain. The stacking fault energy of austenite is low, which provides the driving force for martensitic transformation [17]. The martensitic lath are parallel or cross distributed in austenite grains, as shown in Fig. 7d. Since the $a^{\prime}-\mathrm{M}$ formations with different orientation overlap within the austenite, an increased volume of martensitic transformation causes a corresponding reduction of austenite, which not only influences the motion of the dislocations, but also reduces the number of twin formations. Meanwhile, More stacking faults in austenite promote the accumulation of solute atoms at the stacking faults, which increase the resistance of deformation dislocation expansion to play a strain strengthening effect [14]. The deformation dislocation, micor-shear band and their intersection location will become the preferential nucleation area of martensitic transformation [15]. The 
original grains in HAZ are elongated and the grains are broken with the grain boundaries disappeared after strain. A similar observation was reported by Lee and Lin [18], who stated that dense deformation slip bands and finer lath martensite were found in the grains under the larger strain.

The formation of martensite depends on stacking fault energy. With the increase of stacking fault energy, stacking fault overlap becomes more and more irregular to make martensite nucleation difficult [19]. Figure 8 shows the $\mathrm{a}^{\prime}-\mathrm{M}$ formation in austenite during strain. It is noted that origin of $\mathrm{a}^{\prime}-\mathrm{M}$ is dislocation and then occurrence of dislocation increment is found in the deformed microstructure under strain, refer Fig. 8b. When dislocations are more and more, the different dislocation will meet and merge each other, refer Fig. 8c. The dynamic mechanical behavior at a specific strain can be associated with the workhardening stress, which in turn is related to the dislocation density. At this time, some stacking faults form and they are parallel in austenite grain, which provides driving force to $a^{\prime}-M$ formation, refer Fig. 8d. It suggests that the stacking faults act as precursor to the deformation-induced formation of $\mathrm{a}^{\prime}-\mathrm{M}$ at larger strain of $13 \%$. Meanwhile, some dislocations and even stacking faults with different orientation occur and they slip to form martensite lath with deformation, refer Fig. 8e. Finally, the martensite lath with network is shown in austenite grain, refer Fig. $8 f$.

The microstructure evolutions in the HAZ of $304 \mathrm{~L}$ joint reveal that the $\mathrm{a}^{\prime}-\mathrm{M}$ structures and micro-shear bands are both formed in the austenite grain experiencing strain by $13 \%$. This is attributed to the motion of different orientation dislocation under the condition of deformation. It is also noted that the larger deformation is in the joint, the finer martensite lath can be formed.

\subsection{Effect on mechanical properties}

The present microstructural observations provide insights into the evolution of the dislocation slip and martensite transformation after strain. However, it is also desirable to study the effect of strain on mechanical properties of weldment in order to better understand the characteristics of the $304 \mathrm{~L}$ steel joint by PAW + GTAW under high strain deformation. Figure 9 depicts that tensile strength is greatly different between the joint as welded (AW) and that after strain (AS). It is also noted that there is a significant effect of strain on tensile strength and fracture location of 304L steel weldment at both room temperature $25^{\circ} \mathrm{C}$ and low temperature of $-196^{\circ} \mathrm{C}$.

It can be seen that the tensile strength of $304 \mathrm{~L}$ steel weldment as welded is $700 \mathrm{MPa}$ and the fracture occurs in the $\mathrm{HAZ}$ at $25^{\circ} \mathrm{C}$. The tensile strength increases to $804 \mathrm{MPa}$ after strain. This suggests that joint has an obvious strengthening of $104 \mathrm{MPa}$ induced by strain and it is more apparent at $-196^{\circ} \mathrm{C}$. The tensile strength increases from $1480 \mathrm{MPa}$ to $1700 \mathrm{MPa}$ and the fracture occurs on the base metal, refer Fig. $9 \mathrm{~b}$. It is related to transformation of $a^{\prime}-M$ with high hardness phase at larger strain of $13 \%$ in HAZ. Meanwhile, there are in a large number of dislocations and twins in the austenite grains. Compared to $304 \mathrm{~L}$ steel joint as welded fracturing in $\mathrm{HAZ}$, deformation of in the weld metal and base metal is smaller.

In addition, the dislocation accumulation and increment in austenitic grain may form cellular structure, and the deformation twins produced in the process of strain can also induce strengthening effect, which improves the strength of $304 \mathrm{~L}$ steel weldment. There is obvious necking phenomenon in the tensile 
fracture at $25^{\circ} \mathrm{C}$, as shown in Fig. $10 \mathrm{a}$. However the fracture at low temperature of $-196^{\circ} \mathrm{C}$ is relatively flat, and the martensitic transformation structure shows greater brittleness under low temperature stress, as shown in Fig. $10 \mathrm{~b}$. The tensile fracture morphology at $-196^{\circ} \mathrm{C}$ is obvious brittle feature with much more cleavage step pattern.

Figure 11 shows the impact absorption energy of $304 \mathrm{~L}$ weld joint at low temperature $\left(-196^{\circ} \mathrm{C}\right)$. It is noted that the impact toughness in base metal (BM), the heat affected zone (HAZ) and weld metal (WM) decreases after strain treatment. Especially, the impact toughness in HAZ reduces to $94 \mathrm{~J}$ from $116 \mathrm{~J}$ as welded. This can be explained by the microstructure characteristics after strain. There are a lot of ferrite in the WM which can limit the sharp decreasing of ductility and toughness. The grain boundary can prevent the dislocation from slipping resulted to higher impact toughness than that in HAZ. While the less impact toughness in HAZ is mainly due to the formation of deformed martensite with high strength, high hardness and low toughness. The crystal distortion and dislocation density increase in austenite grain after strain strengthening, which leads to the decrease of impact toughness at $-196^{\circ} \mathrm{C}$. These deformed martensite lath and dislocations accumulated at grain boundaries result in stress concentration and impact toughness reduction after strain. The fracture morphology with more deep cleavages is also shown in Fig. 11b compared to that as welded.

Figure 12 shows the representative impact fracture surfaces of the specimens both notched at the weld metal (WM) and the heat affected zone (HAZ) under the condition of as welded and after strain. As shown in Fig. 12a and Fig. 12b, most of pattern is dimple zone in fracture surface of WM as welded and there are fewer tearing with elongated dimple shown in WM after strain. The stress-fracture regions as welded are covered with $\sim 5 \mu \mathrm{m}$-diameter and $\sim 50 \mu \mathrm{m}$ diameter dimples. The small-dimple area in the specimen as welded shows deep holes and the corresponding impact toughness is up to 122 J. A comparison of the fracture surfaces of the specimens strained shows that the area of dimple is less with more obvious tearing feature than that in as welded specimens. The diameter of the large dimples increased with decreasing small-dimple area. The strain conducted has decreased the average size of the dimples in WM.

Figure 12c shows the fracture morphology of impact toughness tested specimens in HAZ as welded. It is a mixture of dimple and few quasi-cleavages, which reflects an interaction between the cleavage cracks and grains suffered plastic deformation [20]. Dimple fracture is a known kind of ductile fracture which occurs during high energy absorption process. However, quasi-cleavage is a kind of brittle fracture. It can be concluded that the fracture of the as welded specimen exhibits a mixed-mode of brittle and ductile rupture. Large numbered cleavage steps occur in the impact fracture surface after strain specimens as shown in Fig. 12d. In comparison to Fig. 12c, the cleavage area is found to be larger, which indicated an identical brittle fracture feature with less toughness after strain. This is distributed in the true strain treated by $13 \%$ deformation in HAZ. There are a lot of micro defects such as dislocations in the grain caused by martensite sheared in HAZ after strain, which leads to the stress concentration and the formation of microcracks in the process of impact loading. The micro-crack accelerates the crack growth and is unfavorable to the impact toughness. 


\section{Conclusion}

In the present work, the effects of strain on the microstructure evolution, tensile properties and impact toughness at a low temperature of $-196^{\circ} \mathrm{C}$ of SUS $304 \mathrm{~L}$ stainless steel wledments were investigated using pre-strained specimens containing the weld metal (WM), the heat affected zone (HAZ) and base metal (BM), which was achieved by PAW + GTAW process. The conclusions can be summarized as follows:

(1) The deformation of 304L joint shows inhomogeneity at an average strain by $9 \%$. The deformation of the weld metal is only $3 \%$ and it is $13 \%$ in the heat affected zone.

(2) The skeletal delta ferrite in the weld metal for GTAW covering layer becomes fine and dense with decreasing ferrite lath gap along the deformation and crystal orientation of austenite in PAW backing layer is elongated along the deformation direction after strain.

(3) There are martensite formations and micro-shear bands occurring in the HAZ regions of the weldments after strain and the finer martensite lath are cross distributed in austenite under the larger strain of $13 \%$.

(4) The origin of a'-M transformation in HAZ is dislocation and then occurrence of dislocation increment is found in the deformed microstructure. Subsequently, stacking faults act as precursor to the deformation-induced formation of $\mathrm{a}^{\prime}-\mathrm{M}$ at strain and some stacking faults with different orientation occur and they slip to form martensite lath with lager deformation.

(5) There is a significant effect of strain on tensile strength. The tensile strength of $304 \mathrm{~L}$ steel weldment as welded is $700 \mathrm{MPa}$ and it increases to $804 \mathrm{MPa}$ after strain. Meanwhile, strengthening is more apparent at $-196^{\circ} \mathrm{C}$ and the tensile strength increases from $1480 \mathrm{MPa}$ to $1700 \mathrm{MPa}$ in specimen after strain.

(6) The impact toughness at $-196^{\circ} \mathrm{C}$ in base metal, the heat affected zone and weld metal decreases after strain treatment, especially the impact toughness in HAZ sharply reduces to $94 \mathrm{~J}$ from $116 \mathrm{~J}$ as welded. Correspondingly, a mixed-mode of brittle and ductile rupture as welded is also changed into large numbered cleavage steps after strain.

\section{Declarations}

\section{Acknowledgements}

The authors gratefully acknowledge the financial support provided to this study by the National Nature Science Foundation of China囚Grant No.52075295区, Nature Science Foundation of Shandong Province (Grant No.ZR2019MEE117 \& Grant No.2019JZZY010366).

\section{Ethical Approval}


The submitted work is original and not has been published elsewhere in any form or language. The manuscript is not submitted to more than one journal for simultaneous consideration.

\section{Consent to Participate}

Not applicable.

\section{Consent to Publish}

Not applicable.

\section{Authors Contributions}

All authors read and approved the final manuscript.

\section{Funding}

This work was supported by the National Nature Science Foundation of China『Grant No.52075295区, Nature Science Foundation of Shandong Province (Grant No.ZR2019MEE117 \& Grant No.2019JZZY010366).

\section{Competing Interests}

Not applicable.

\section{Availability of data and materials}

The data and materials used and/or analyzed during the current study are included in this article and they are available from the corresponding author on reasonable request.

\section{References}

1. Kinoshita K (2015) Influence of tensile stress on permeability properties of type 304 stainless steel. J Appl Phys 117(17):713-717 https://doi.org/10.1063/1.4913819

2. Paul SF, David JG, John M, Edward R (2011) A lower-bound temperature and strain-rate dependent strength model for AISI 304 SS. Journal of pressure vessel technology-transactions of the ASME 133(5):113-120 https://doi.org/10.1115/PVP2011-57399

3. Farias F, Alvarez-Al, Armas AF (2020) On the strain-induced martensitic transformation process of the commercial AISI 304 stainless steel during cyclic loading. Int J Fatigue 140:18 https://doi.org/10.1016/j.jijatigue.2020.105809

4. Lee YH, Wu KL, Jhou JH, Tsai YH, Yan BH (2013) Two-dimensional vibration-assisted magnetic abrasive finishing of stainless steel SUS304. Journal of Advanced Manufacturing Technology 69: 2723-2733 https://doi.org/10.1007/s00170-013-5242-0 
5. Toma RE, Brandi SD, Souza AC, Morais Z (2011) Comparison between DC(+) and square wave AC SAW current outputs to weld AISI 304 for low-temperature applications. Welding Journal 90(9):153160 https://doi.org/0000-0002-8460-1297

6. Ravisankar A, Velaga SK, Rajput G, Venugopal S (2014) Influence of welding speed and power on residual stress during gas tungsten arc welding (GTAW) of thin sections with constant heat input: $A$ study using numerical simulation and experimental validation. Journal of Manufacturing Processes 16(2):200-211 https://doi.org/10.1016/j.jmapro.2013.11.002

7. Wang BM, Chen T, Xu T, He H (2013) Influence of welding technology on strain strengthening properties of austenitic stainless steel welded joints. Pressure Vessel Technology 30(4):2933 https://doi.org/10.3969/j.issn.1001-4837.2013.04.006

8. Kang N, Singh J, Kulkarni AK (2006) Gravitational effects on the gas tungsten arc welds of 304 stainless steels. Mater Manuf Processes 18(4):549-561 https://doi.org/10.1081/AMP-120022496

9. Harish TM, Jerome S, Yadukrishna B, Kumar RS, Midhun SC, Ramesh K (2019) Assessment of microstructure and mechanical properties of keyhole plasma arc welded similar butt joint of AISI 304H austenitic stainless steel. Materials Research Express 6(11):1-8 https://doi.org/10.1088/20531591/ab4e04

10. Mahrle A, Rose S, Schnick M, Beyer E, Füssel U (2013) Stabilisation of plasma welding arcs by low power laser beams. Sci Technol Weld Joining 18(4):323328 https://doi.org/10.1179/1362171813Y.0000000109

11. Liu K, Li YJ, Wang J (2016) Microstructure and low-temperature mechanical properties of 304 stainless steel joints by PAW + GTAW combined welding. Journal of materials Engineering performance 25(10):4561-4570 https://doi.org/10.1007/s11665-016-2288-9

12. Mansourinejad $M$, Ketabchi $M(2018)$ Influence of strain state on the kinetics of martensitic transformation induced plasticity (TRIP) in AISI 304 sainless steel. Steel Research international 89(3):359-365 https://doi.org/10.1002/srin.201700359

13. Lee WS, Lin CF, Cheng CW (2004) The effects of strain rate and welding current mode on the dynamic impact behavior of plasma-arc-welded 304L stainless steel weldments. Metallurgical Materials Transaction A 35(5):1501-1515 https://doi.org/10.1007/s11661-004-0258-6

14. Lee WS, Lin CF, Liu CY, Cheng CW (2007) Effects of strain rate and welding current mode on microstructural properties of SUS 304L PAW welds. Journal of Materials Process Technology 183(2/3):183-193 https://doi.org/10.1016/j.jmatprotec.2006.10.008

15. Talonen J, Hanninen H (2007) Formation of shear bands and strain-induced martensite during plastic deformation of metastable austenitic stainless steels. Acta Mater 55(18):61086118 https://doi.org/10.1016/j.actamat.2007.07.015

16. Moallemi M, Kermanpur A, Najafizadeh A, Rezaee A, Baghbadorani HS, Nezhadfar PD (2016) Deformation-induced martensitic transformation in a 201 austenitic steel: The synergy of stacking fault energy and chemical driving force. Mater Sci Eng A 653:147152 https://doi.org/10.1016/j.msea.2015.12.006 
17. Djamel K, Liu JL (2018) Deformation induced martensitic transformation in stainless steels. Mater Sci Eng A 715:73-82 https://doi.org/10.1016/j.msea.2017.12.036

18. Lee WS, Lin CF (2002) Effects of prestrain and strain rate on the dynamic deformation characteristics of 304L stainless steel. Part II. Microstructural study. Materials Science Technology 18(8):877-884 https://doi.org/10.1179/026708302225004720

19. Hemantha K, Yeddu T, Avadh S (2013) Strain-induced martensite transformation in stainless steels: A three-dimensional phase-field study. Acta Mater 61(18):69726982 https://doi.org/10.1016/j.actamat.2013.08.011

20. Tang L, Qian C, Zou BW (2015) Experimental study of the strain-strengthening effect on the mixed mode notch-crack fatigue propagation in austenitic stainless steel 06Cr19Ni10. Eng Fract Mech 134:54-60 https://doi.org/10.1016/j.engfracmech.2014.12.003

\section{Tables}

Table 1 Chemical compositions of 304L steel and 308LSi filler wire (\%).

\begin{tabular}{|lllllllllll|}
\hline Element & $\mathrm{C}$ & $\mathrm{S}$ & $\mathrm{P}$ & $\mathrm{Si}$ & $\mathrm{Mn}$ & $\mathrm{Mo}$ & $\mathrm{Cu}$ & $\mathrm{Cr}$ & $\mathrm{Ni}$ & $\mathrm{Fe}$ \\
\hline 304L & 0.06 & 0.012 & 0.026 & 0.40 & 1.62 & - & - & 18.03 & 8.14 & Bal. \\
\hline 308LSi & 0.03 & 0.03 & 0.03 & 0.9 & 1,5 & 0.7 & 0.7 & 21.5 & 10.5 & Bal. \\
\hline
\end{tabular}

Table 2 Welding parameters of PAW+GTAW process.

\begin{tabular}{cccccc}
\hline Groove & Process & $\begin{array}{c}\text { Current } \\
\text { I/A }\end{array}$ & $\begin{array}{c}\text { Welding speed } \\
v / \mathrm{cm}^{\circ} \mathrm{s}^{-1}\end{array}$ & $\begin{array}{c}\text { Heat input } \\
E / \mathrm{kJ} \bullet \mathrm{cm}^{-1}\end{array}$ & $\begin{array}{c}\text { Plasma gas } \\
/ \text { shielding gas }\end{array}$ \\
\hline PAW & 280 & 0.35 & 24.0 & $97 \% \mathrm{Ar}+3 \% \mathrm{H}_{2}$ \\
& GTAW & 270 & 0.35 & 22.5 & $100 \% \mathrm{Ar}$ \\
\hline
\end{tabular}

\section{Figures}




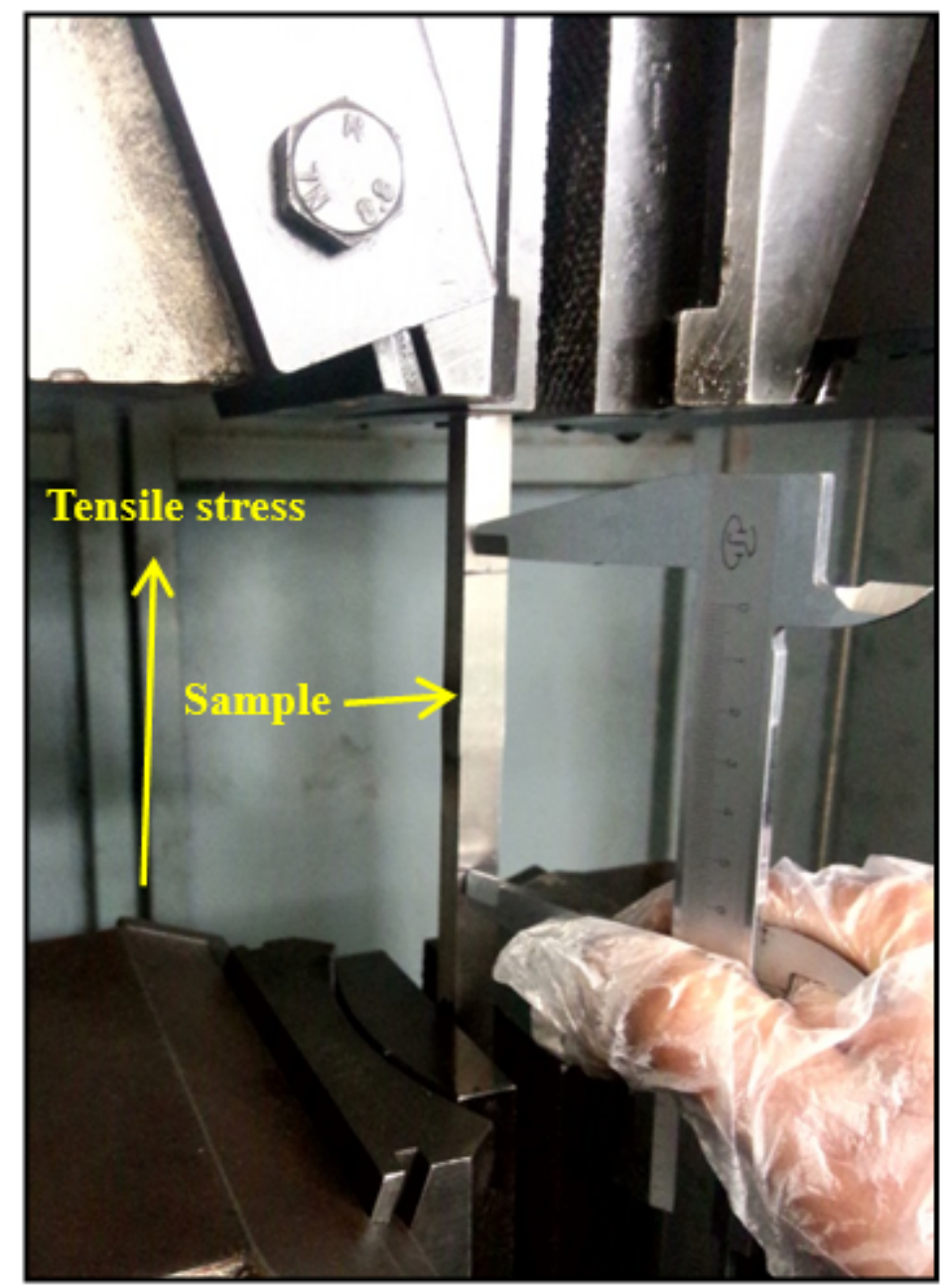

Figure 1

Static tension strain by $9 \%$ on $304 \mathrm{~L}$ joint. 
(a)
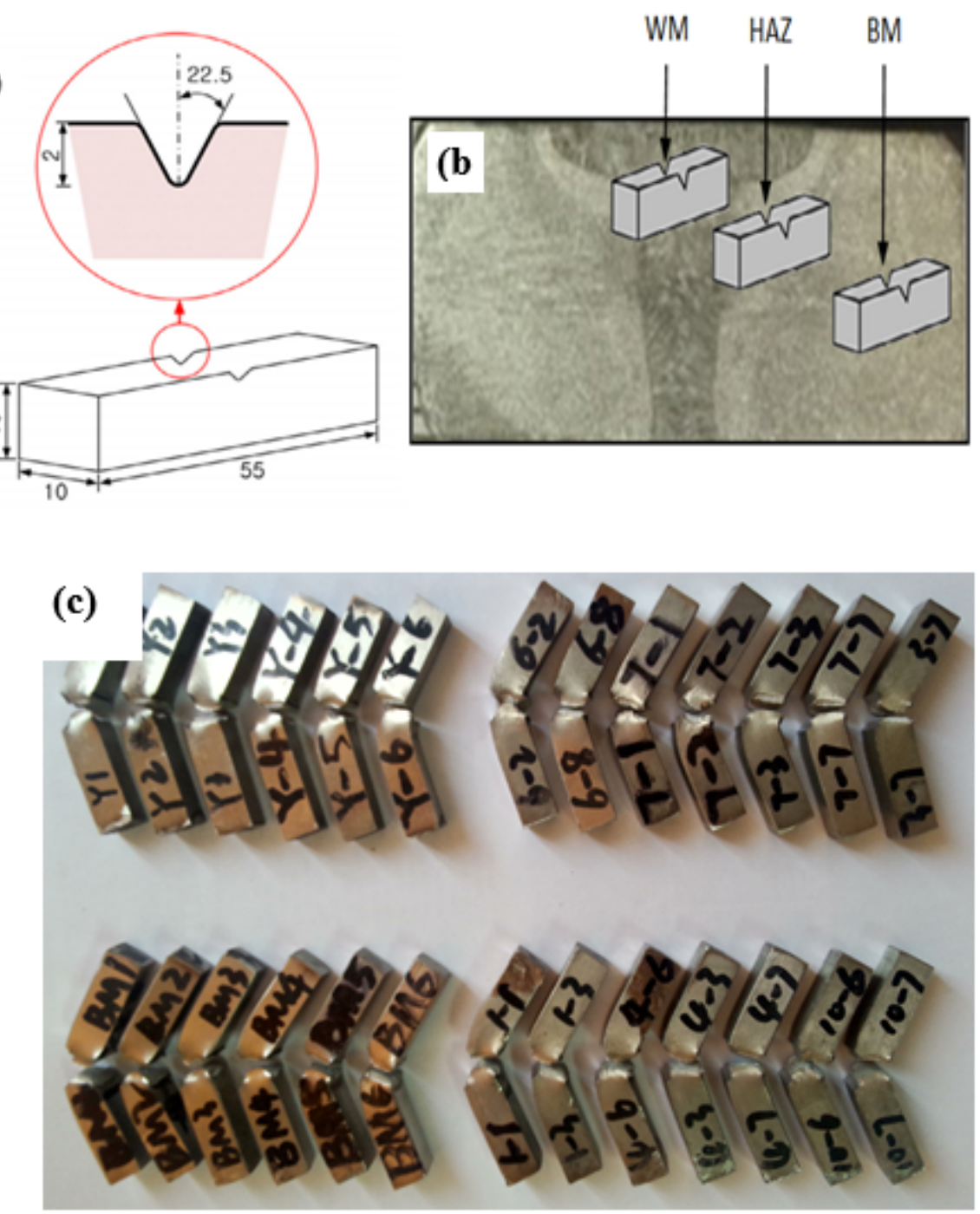

Figure 2

V-notch impact samples: (a) size (b) notch location, and (c) fractured joint.
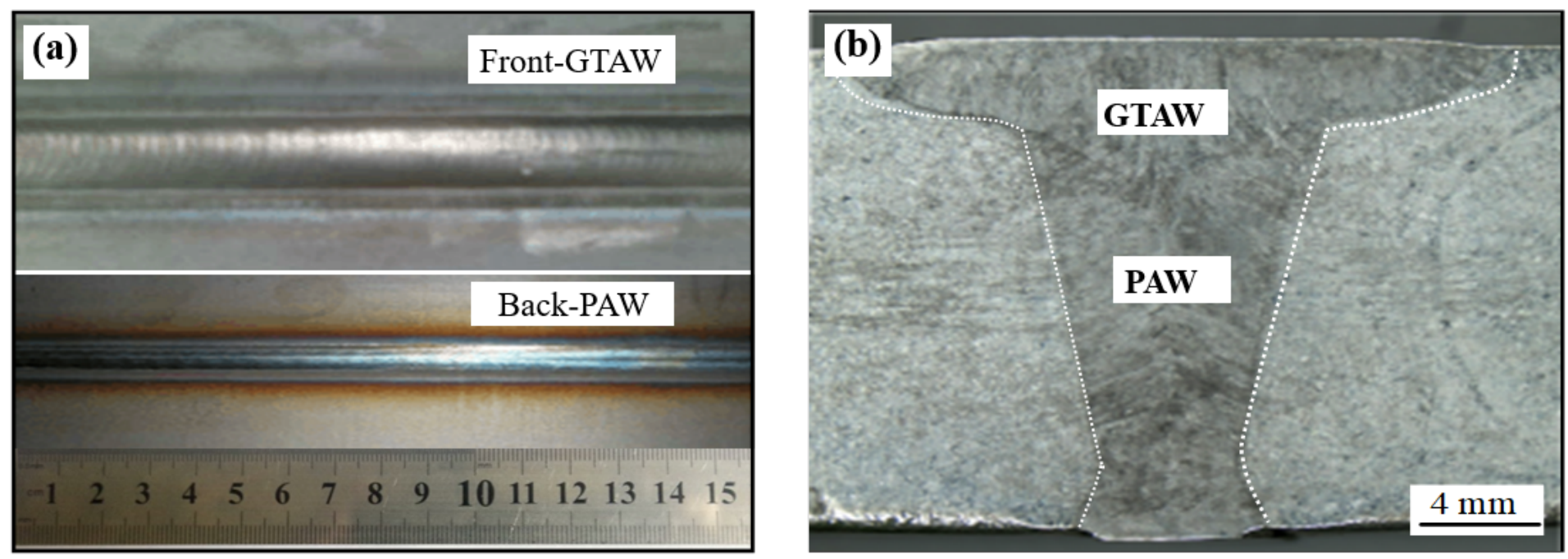

Figure 3 
304L joint by PAW+GTAW: (a) 304L joint morphology and (b) cross-section feature.
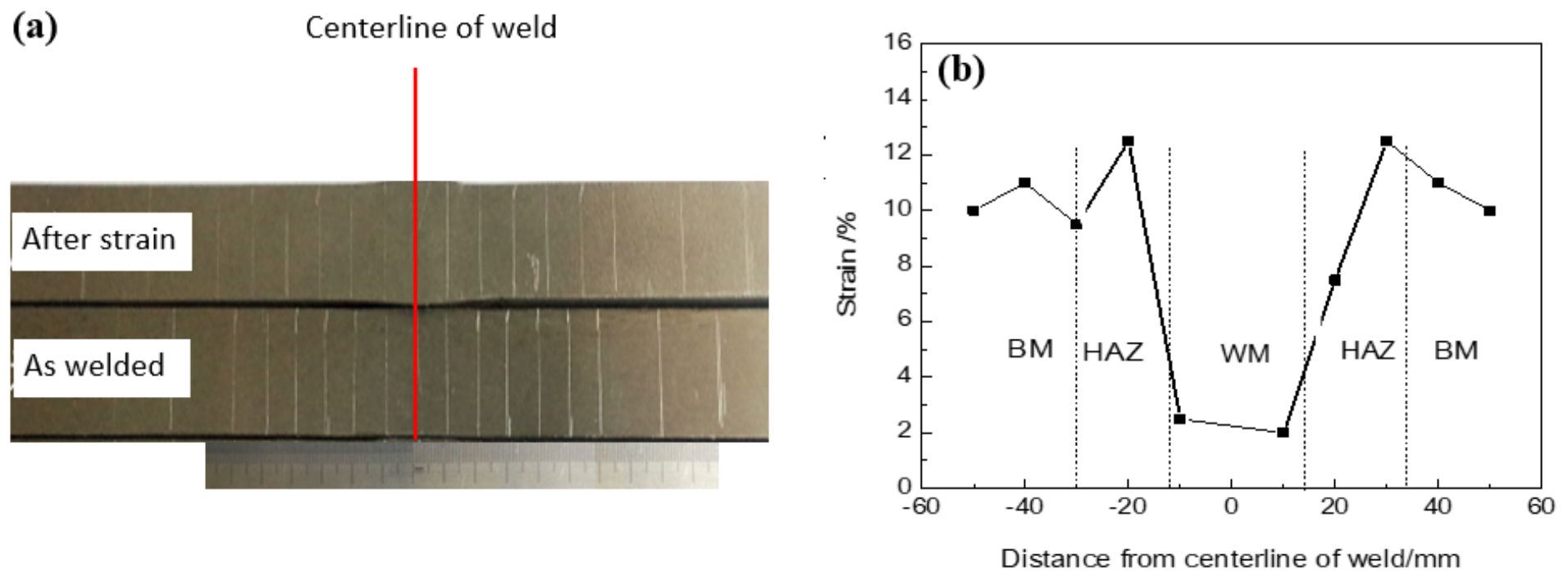

Figure 4

Strain measurement for joint: (a) measure location and (b) strain in different region of joint.
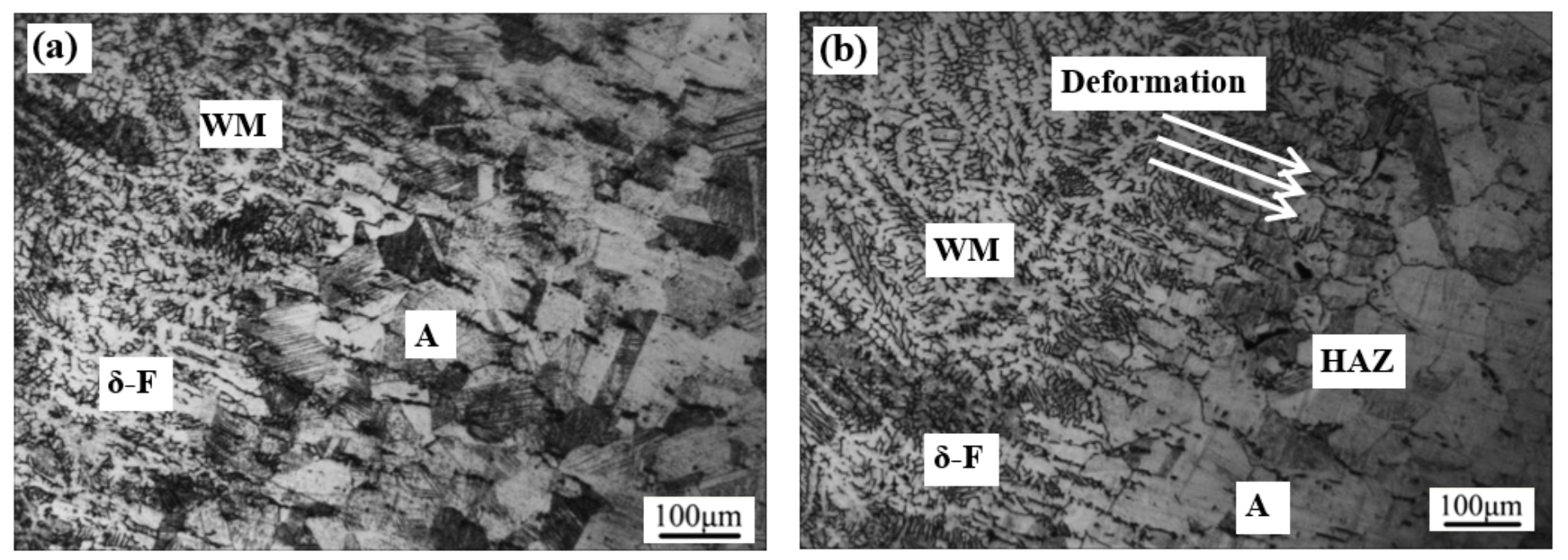

Figure 5

Microstructure in $304 \mathrm{~L}$ joint $\mathbb{( a )}$ as welded and (b) after strain. 

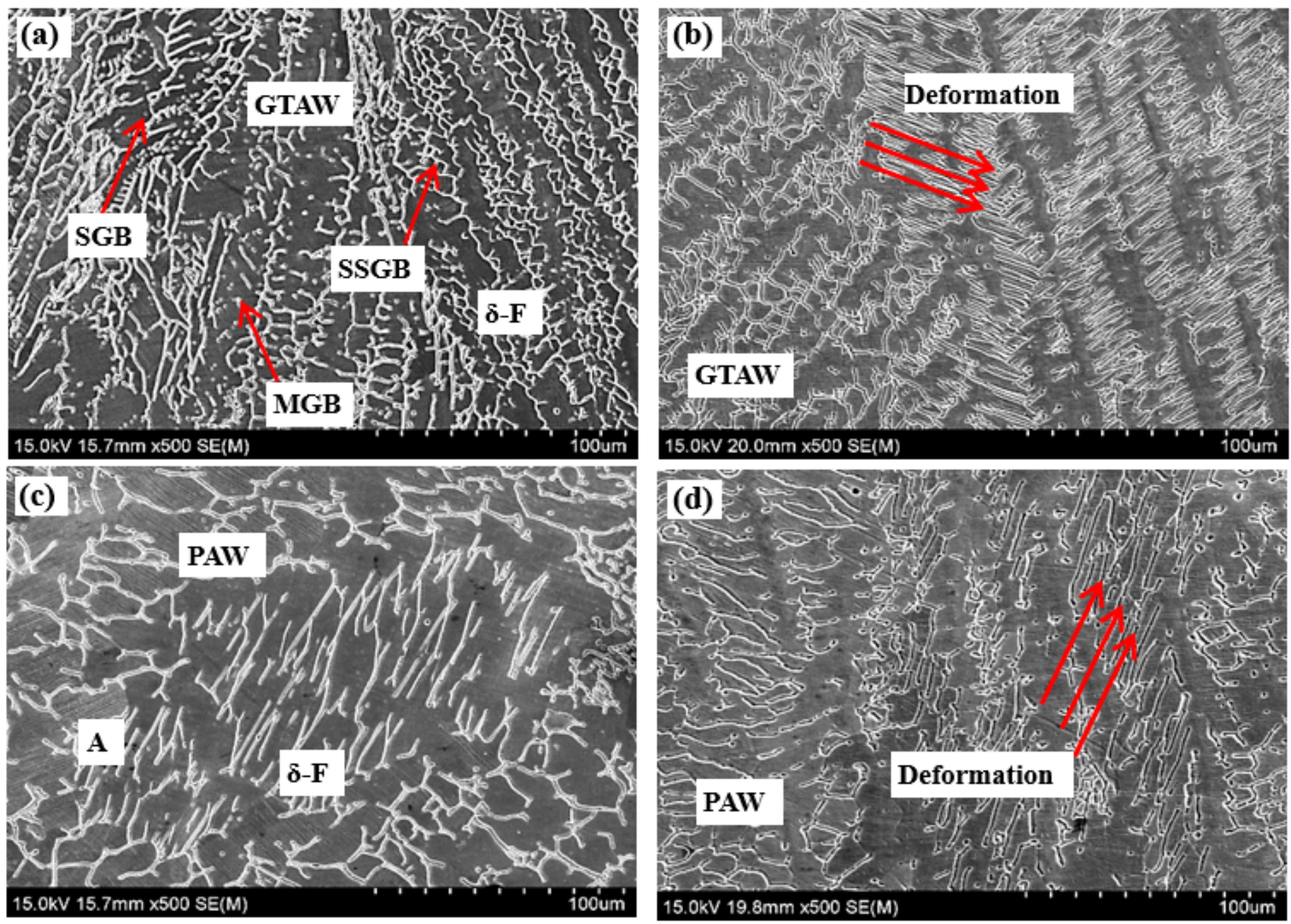

Figure 6

Microstructure characteristic in the weld metal: (a) GTAW as welded, (b) GTAW after strain, (c) PAW as welded, and (d) PAW after strain. 

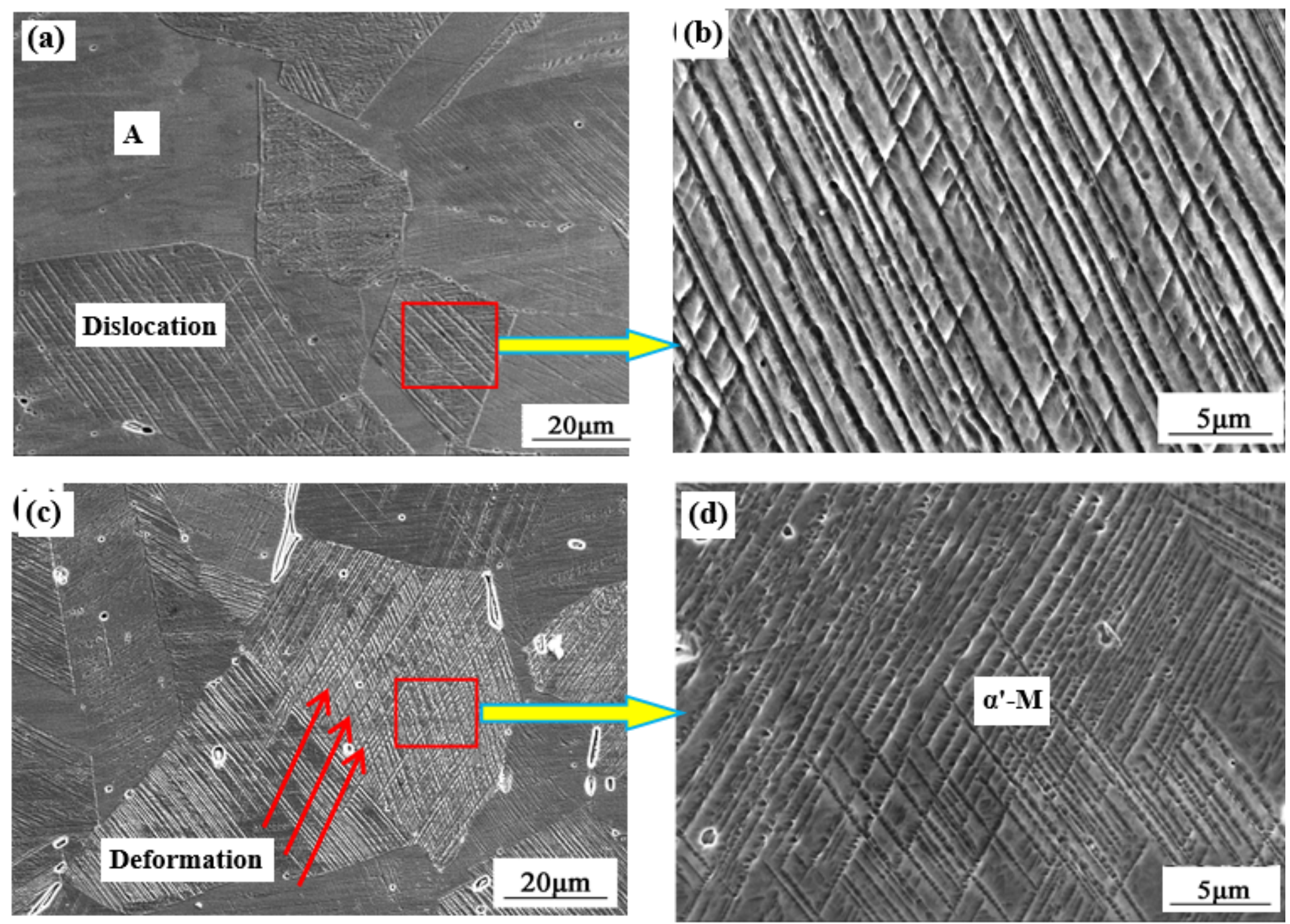

Figure 7

Microstructure characteristic in the HAZ: (a) as welded, (b) grain feature, (c) after strain, and (d) $a^{\prime}-M$. 
(a)
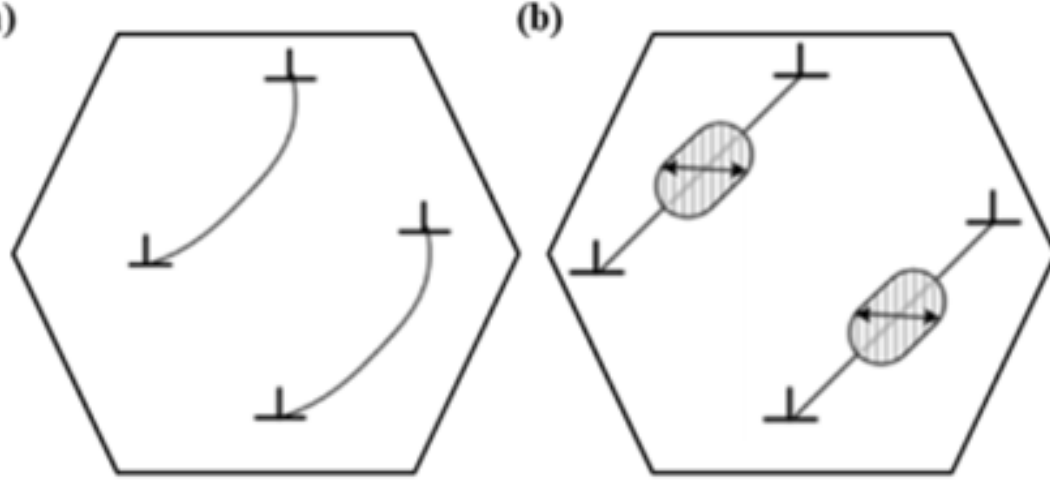

(d)

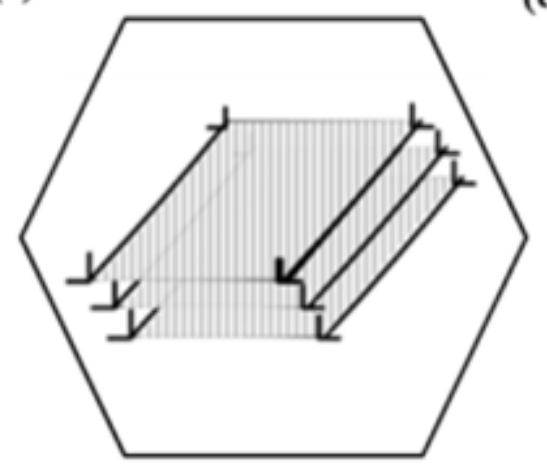

(e)

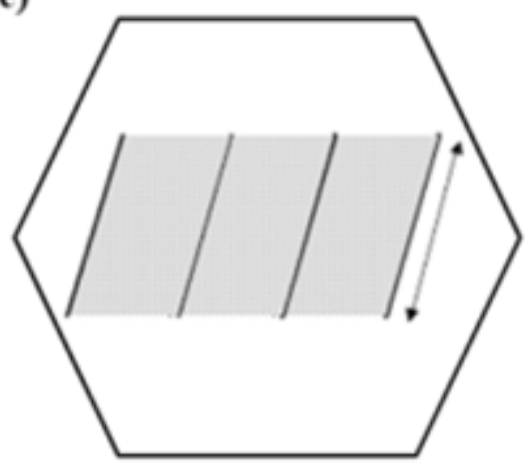

(c)

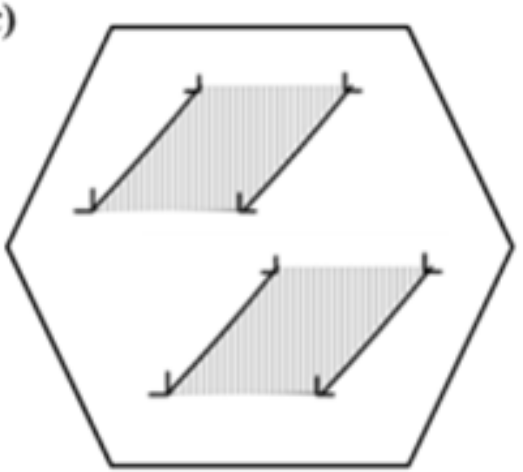

(f)

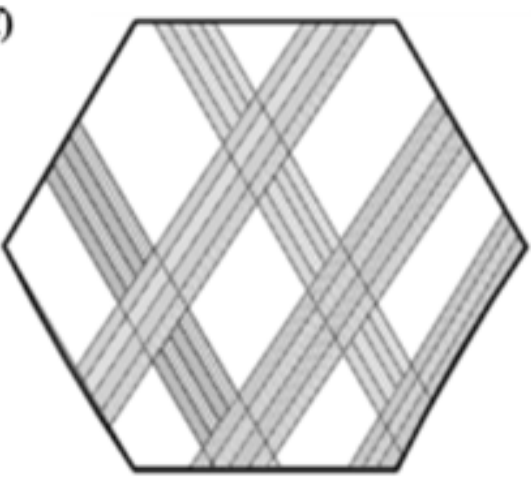

Figure 8

a'-M formation in austenite during strain: (a) Dislocation (b) increment (c) mergence (d) stacking fault (e) slip, and (f) network.

(a)

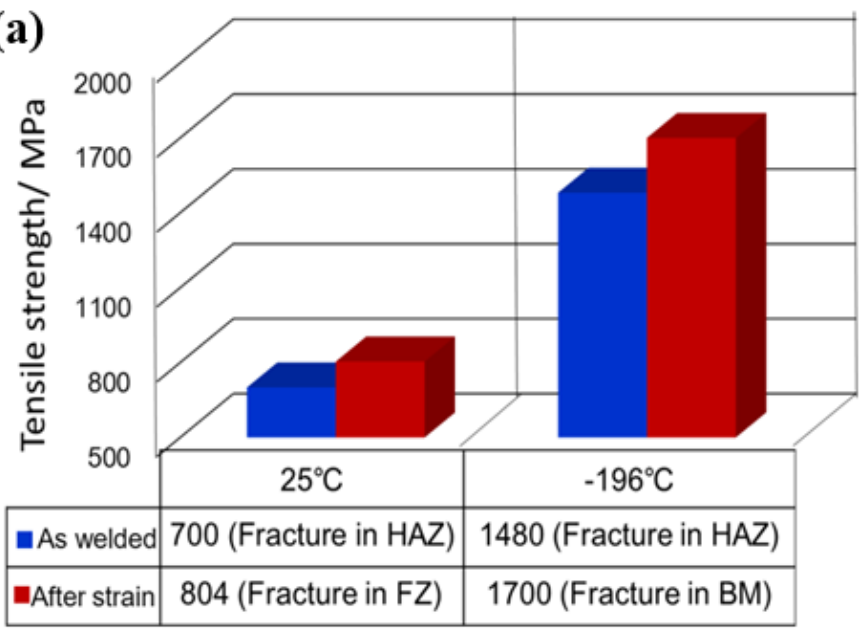

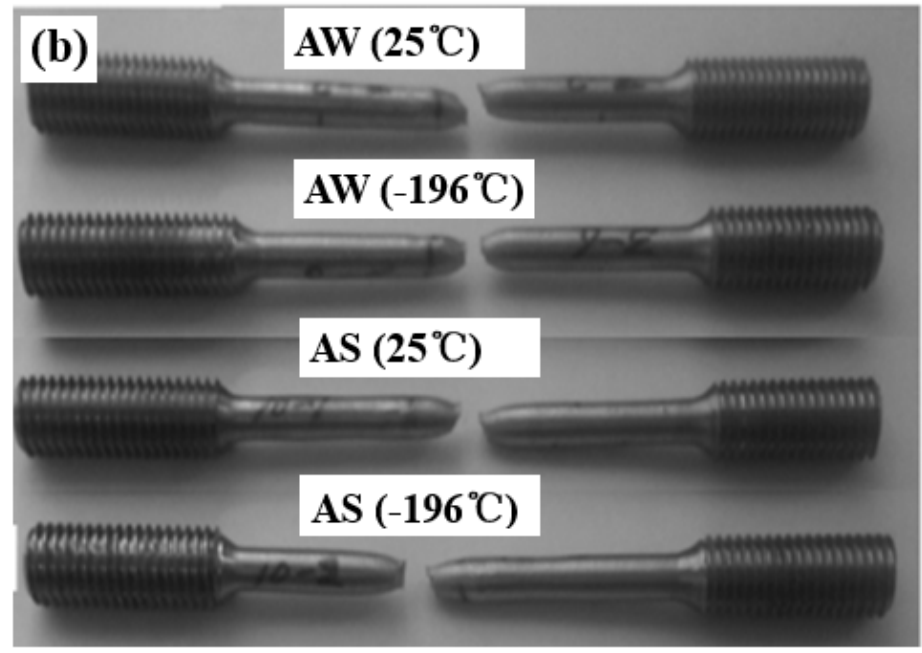

\section{Figure 9}

Tensile strength of 304L joint: (a) effect of strain and (b) fracture location. 

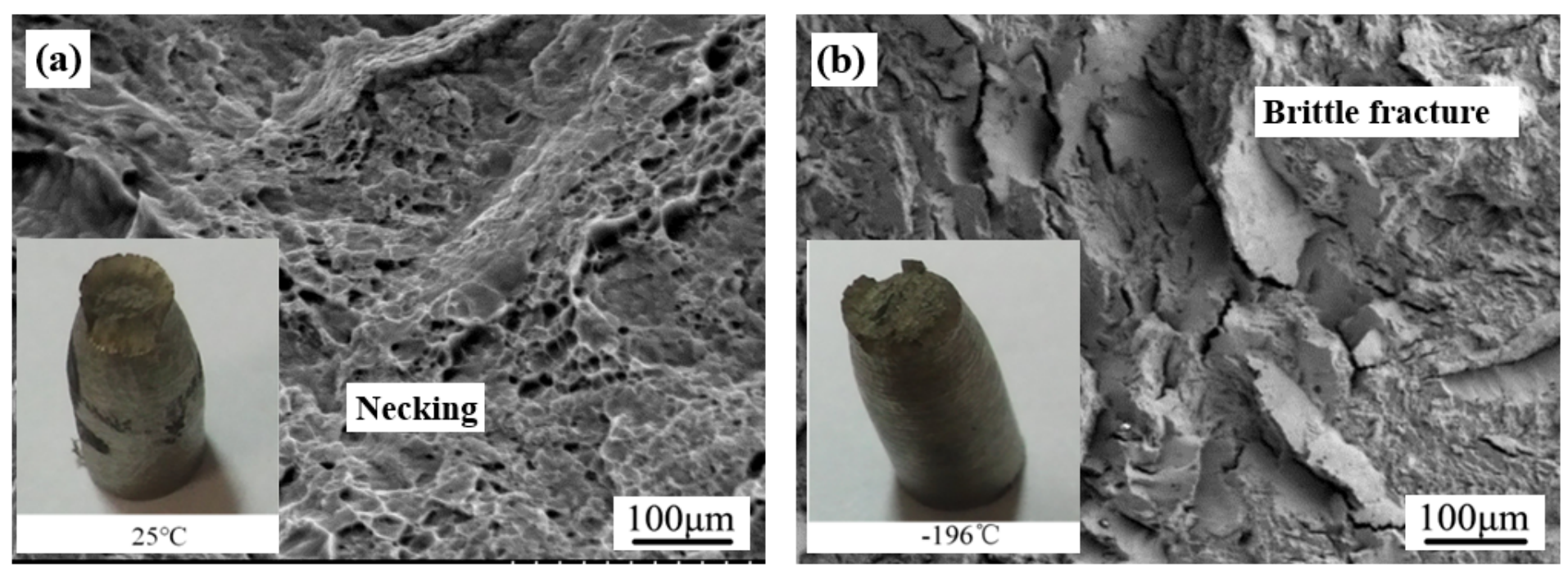

Figure 10

Fracture morphology of joint after strain: (a) at $25^{\circ} \mathrm{C}$ and (b) at $-196^{\circ} \mathrm{C}$.

(a)

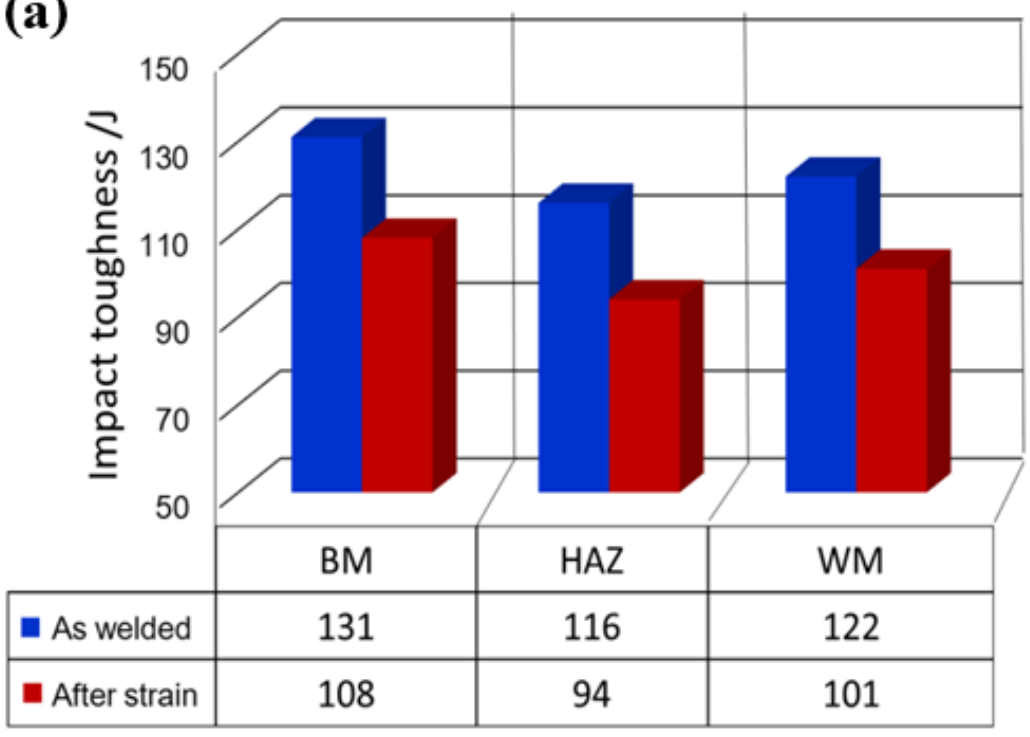

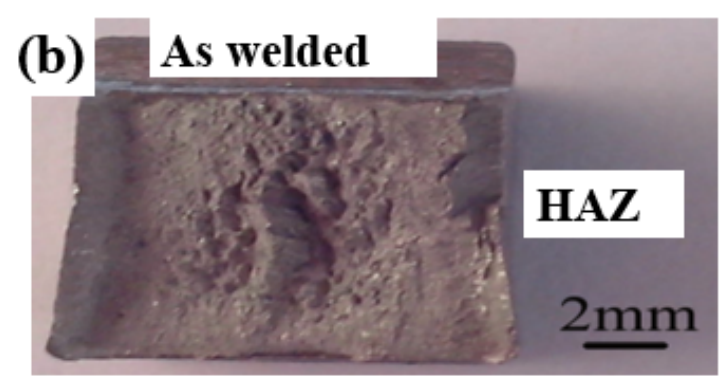

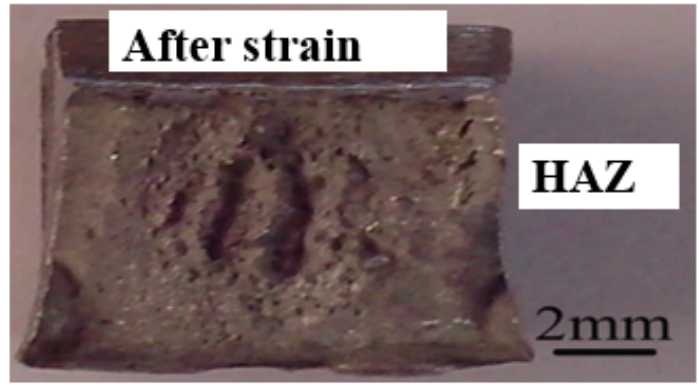

Figure 11

Impact toughness of $304 \mathrm{~L}$ joint at $-196^{\circ} \mathrm{C}$ : (a) effect of strain and (b) fracture morphology. 

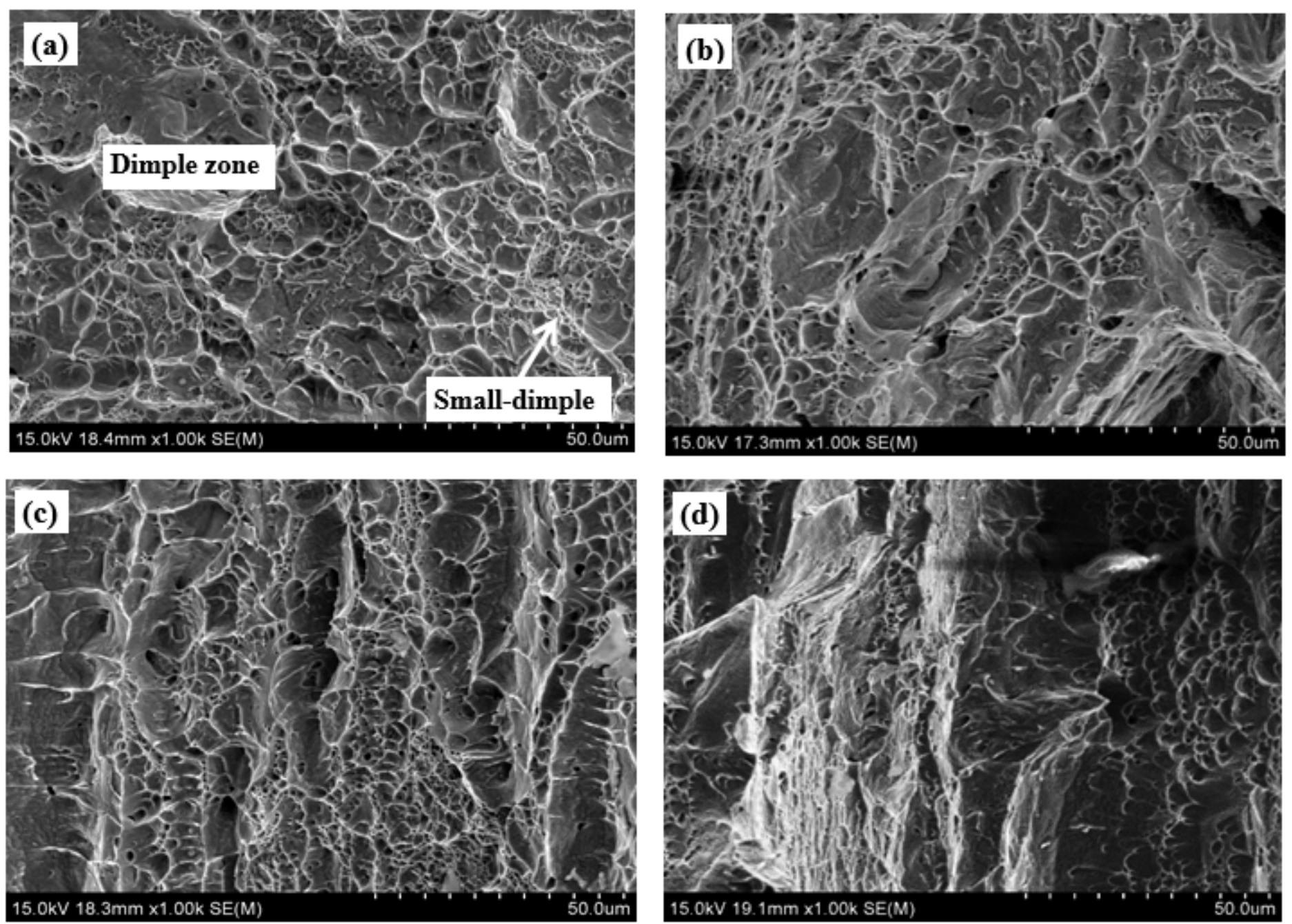

Figure 12

Fracture morphology for impact specimens: (a) WM as welded, (b) WM after strain, (c) HAZ as welded, and (d) HAZ after strain. 